\title{
Micenas na Viena fin-de-siècle: Nietzsche, Freud, Hofmannsthal e o eterno retorno do mito
}

\author{
Mycenae in Fin-de-siècle Vienna: Nietzsche, Freud, Hofmannsthal and the Eternal \\ Return of the Myth
}

Leonardo Munk*

\begin{abstract}
This article aims to investigate the correlation of thought between three leading names in the second half of the nineteenth century - Friedrich Nietzsche, Sigmund Freud and Hugo von Hofmannsthal - that have addressed the crisis of male identity against the return of matriarchy. Considering the Vienna fin-de-siècle as a backdrop, female is presented here through Electra, a mythical heroine. In Hofmannsthal's homonymous play, she represents not only strengthening as the woman's own destruction.
\end{abstract}

Keywords: History; Literature; Psychoanalysis; Austria

Resumo: Este artigo tem por objetivo investigar a correlação de pensamento entre três importantes nomes da segunda metade do século XIX - Friedrich Nietzsche, Sigmund Freud e Hugo von Hofmannsthal - que se debruçaram sobre as crises da identidade masculina frente ao retorno do matriarcado. Tendo a Viena fin-de-siècle como cenário, o feminino é apresentado aqui por intermédio de Electra, que no texto homônimo de Hofmannsthal representa não só o fortalecimento como a própria destruição da mulher.

Palavras-chave: História; Literatura; Psicanálise; Áustria

\footnotetext{
${ }^{*}$ Professor Adjunto do Departamento de Teoria do Teatro e da Escola de Letras da Universidade Federal do Estado do Rio de Janeiro (UNIRIO). E-mail: leonardomunk@ gmail.com.
} 
Além de sua inegável repercussão na vida intelectual do ocidente ao longo de todo o século passado, e isso para além dos estudos estritamente psicanalíticos, A interpretação dos sonhos ${ }^{1}$, obra datada de 1900 - embora tenha sido publicada, de fato, no final do ano anterior (ROUDINESCO 1995: 136) -, pode ser lida como uma notável radiografia da produção artística e cultural europeia na virada do século XIX para o XX e se mostra ainda hoje relevante nos debates acerca da pós-modernidade. Um bom exemplo disso é o livro O mal-estar da pós-modernidade, obra de 1997, cujo autor, o sociólogo polonês Zygmunt BAUMAN (1998: 98) - além da óbvia referência a $O$ mal-estar na civilização, texto de Freud de 1930 -, faz alusão à Interpretação dos sonhos quando diz que "[...] a revolução moderna terminou em parricídio - poeticamente intuído por Freud, no seu desesperado esforço para discernir o mistério da cultura”.

Essa revolução cultural promovida por Sigmund Freud, no entanto, muito se deveu ao solo fértil da Viena de então, germinado por um amálgama de efervescência artístico-cultural e crise sociopolítica que se deixava entrever em várias áreas do conhecimento, abrindo caminho, desse modo, para um gradual enfraquecimento da ortodoxia liberal que se constituíra como principal baluarte da burguesia emancipada do período. Partindo das humanidades às ciências médicas, e fruto de uma atmosfera de crescente inquietação, um mesmo princípio norteador se fazia presente na obra de nomes tão díspares como Gustav Klimt, Arnold Schönberg, Hugo von Hofmannsthal, Karl Kraus, entre outros. Refiro-me ao questionamento da razão burguesa enquanto um elemento homogêneo e indivisível, e da subsequente crise de identidade masculina que se seguiu a esse fenômeno.

Ameaçada frente ao fortalecimento de outras identidades - como a feminina e a judia -, essa compreensão implicou o forte acirramento das tensões entre a estabelecida cultura liberal novecentista e uma nova sensibilidade que, indiferente a qualquer autoridade histórica, expunha inexoravelmente as fragilidades políticas, sociais e, sobretudo, psicológicas da então capital do Império Austro-Húngaro. Acerca disso, o historiador Carl E. SCHORSKE, em um clássico estudo sobre o tema publicado em 1981, argumenta o seguinte em sua introdução:

\footnotetext{
${ }^{1}$ A propósito da relevância deste texto para o conjunto da obra de Sigmund Freud, Patrick J. Mahony, Professor Emérito da Universidade de Montreal e psicanalista, diz que: “(...) há muitas razões para afirmar que o restante da obra de Freud não passou de uma extensão da Interpretação dos sonhos e de sua auto-análise" (MAHONY In ROTH 2000: 40).
} 
Munk, L. - Micenas na Viena fin-de-siècle

Viena no fin-de-siècle, sentindo profundamente os abalos da desintegração
social e política, revelou-se um dos terrenos mais férteis para a cultura a-
histórica do nosso século. Seus grandes inovadores intelectuais - na música e
filosofia, na economia e arquitetura e, evidentemente, na psicanálise -
romperam, todos eles, e de modo mais ou menos deliberado, seus laços com a
perspectiva histórica essencial para a cultura liberal novecentista em que foram
gerados (SCHORSKE 1990: 14).

A expressão "cultura a-histórica" deve ser aqui compreendida como contraponto a uma tendência predominante na historiografia da época: a abordagem teleológica da história. O recorrente recurso ao mito, encontrável em grande parte da obra de intelectuais e artistas vienenses, revestia-se justamente de uma crítica a essa concepção de um desenvolvimento linear e progressivo da história. O eco de Friedrich Nietzsche é aqui plenamente reconhecível visto que sua estratégia anti-historicista era precisamente alimentada pela valorização do mito. Sobre esse ponto, Ernani CHAVES, professor de filosofia da Universidade Federal do Pará, faz o seguinte comentário:

[...] a valorização do mito permite a Nietzsche combater, ao mesmo tempo, em duas frentes: primeiro, contra uma concepção "histórico-natural" da linguagem, esquecida de suas raízes míticas e, segundo, contra a historiografia triunfante do século XIX, que via um corte radical entre Mito e Logos (CHAVES In DUARTE [et al.] 2002: 167).

Contrapondo-se ao influente espírito positivista que seduzia os estudos historiográficos da época - exemplificados particularmente pelas figuras do historiador alemão Theodor Mommsen e do filólogo clássico Wilamowitz-Moellendorf, ambos docentes da Universidade Humboldt de Berlim -, a crítica de Nietzsche se alinhava, por sua vez, ao pensamento de dois autores suíços que, como ele, haviam também lecionado na Universidade da Basiléia: o jurista e antropólogo Johann Jakob Bachofen e o historiador e filósofo Jacob Burckhardt. Comum a ambos era a percepção de que o processo histórico não se constituía de modo algum como sinônimo de progresso (SCHORSKE 2000: 85).

Nesse contexto marcado pela noção de desenvolvimento imposta pela ascensão do modelo prussiano, o caminho tomado pelos artistas e intelectuais que constituíram a chamada "Modernidade Vienense" parecia levar a outro lugar. Lugar este que, distanciando-se da influência da cultura alemã, se associaria à ideia de decadência e dissolução, não apenas política e social, mas, sobretudo, estética. Atrasada em relação 


\section{Munk, L. - Micenas na Viena fin-de-siècle}

às outras grandes capitais europeias em função de suas estruturas econômicas, sociais e políticas, Viena era frequentemente preterida por Londres, Paris e Berlim. Não era, portanto, casual o ambíguo desprezo com que muitos se dirigiam a Viena, uma vez que esse mesmo sentimento, exemplificado aqui na fala de Hugo von HoFMANNSTHAL (apud LE RIDER 1993: 29) - que em carta ao amigo escritor Richard Beer-Hofmann dizia que "a vida que levamos em Viena é nefasta" -, também foi responsável pela formação de uma identidade cultural específica de Viena e da Áustria.

Esse desejo de fuga que acompanhou os vienenses do fim do século XIX foi sintomaticamente acalentado durante muito tempo por Sigmund Freud, e sua vontade de emigrar para Londres foi registrada em carta à sua futura esposa Martha Bernays. Profundamente insatisfeito com sua carreira em função dos obstáculos que enfrentava como resultado de sua condição judaica, Freud queria desesperadamente escapar da sombra da torre da Catedral de Santo Estêvão, símbolo máximo do catolicismo dos Habsburgo (SCHORSKE 2000: 216-7). Era o ano de 1882 e o questionamento dos direitos adquiridos pelos judeus ao longo das décadas de 1850 e 1860 parecia desmentir a tão desejada assimilação ao Império Austro-Húngaro. Em seu ensaio de 1980, Schorske nos dá uma excelente visão do panorama político da época.

O Império Habsburgo estava se desfazendo em suas costuras internas, como a Europa se desfazia internacionalmente: nas linhas verticais da nacionalidade e nas linhas horizontais da classe e da ideologia. Até os anos 1890, as forças políticas em confronto tinham sido as clássicas: liberais versus conservadores. Mas agora estratos sociais inferiores geravam forças para contestar o poder das elites mais antigas. Do operariado surgiu o socialismo; da classe média baixa e do campesinato surgiram o nacionalismo e o socialismo cristão virulentos. A queda de Viena nas mãos dos anti-semitas de Karl Lueger, nas eleições de 1895, foi um golpe atordoante nos defensores judeus e gentios da cultura liberal. As forças do preconceito racial e do ódio nacional, que se julgavam dissolvidas pela luz da razão e domínio da lei, ressurgiram com um ímpeto avassalador, enquanto o "século do progresso" soltava seu último suspiro (SCHORSKE 1990: 182-3).

Único elemento verdadeiramente unificador da elitista educação austríaca, o estudo da cultura greco-romana era o principal pilar para a construção de uma efetiva cultura liberal. Como observaram tanto SCHORSKE (2000: 215) quanto o historiador francês Jacques LE RIDER (1993: 250), o interesse pelos estudos da Antiguidade proporcionou a cristãos e judeus um campo comum onde se podia, de fato, coexistir.

Contudo, e isso muito em função do fracasso do otimismo político e social do período, a Antiguidade revista pelos intelectuais e artistas austríacos dessa nova geração 


\section{Munk, L. - Micenas na Viena fin-de-siècle}

se caracterizou por um perfil distinto daquele valorizado pela geração das décadas de 1850 e 1860. Ao contrário desta última, confiante no progresso e nos aspectos positivos de uma educação baseada exclusivamente em princípios racionais, a geração a que pertenciam Hofmannsthal e seus conterrâneos rejeitou a Grécia Clássica e, como que emulando a revolta edípica coletiva de Freud, voltou-se para o recém-descoberto mundo das civilizações pré-helênicas, com suas narrativas míticas e estruturas arcaicas. À descoberta dos lendários sítios arqueológicos de Tróia e Micenas pelo arqueólogo alemão Heinrich Schliemann, a partir da década de 1870 (LE RIDER 1993: 251), somouse, por conseguinte, o interesse pela Grécia intranquila de Nietzsche e, por extensão, pelo resgate do trabalho precursor de Johann Jakob Bachofen.

Em um ensaio sobre Bachofen datado de 1936 e escrito em francês, Walter Benjamin se refere a ele não apenas como um pioneiro nos estudos da mulher e da ginecocracia - isto é, governo das mulheres -, mas acima de tudo como um "profeta", o anunciador de uma predisposição que seria amplamente retratada pelos modernos de Viena. Refiro-me ao fenômeno que, percebido com dissabor por alguns autores, entre os quais o sueco August Strindberg ${ }^{2}$, Otto Weininger, autor do influente livro Sexo $e$ Caráter, e Karl Kraus, escritor e editor da revista $A$ Tocha, pôs em xeque a certeza de que todas as riquezas espirituais e materiais da humanidade fossem resultado do gênio masculino.

Nessa perspectiva, o fin-de-siècle vienense testemunhou com profundo assombro o retorno de um princípio materno há muito tempo reprimido. Acerca disso, é relevante chamar a atenção aqui para uma observação de Muriel DIMEN (In ROTH 2000: 188), psicanalista e professora da Universidade de Nova Iorque, de que "[...] o fim do século XIX e início do século XX foram a pátria temporal da primeira onda do feminismo". Nesse cenário intelectual altamente regressivo e cultor de uma clara misoginia, é certo que se pode atribuir sem muitos equívocos a má recepção de $O$ matriarcado: investigação sobre a ginecocracia do mundo antigo em seus aspectos religiosos e jurídicos, publicada por Bachofen em 1861, à antecipação em algumas décadas desse retorno das mães no final do século XIX.

\footnotetext{
${ }^{2}$ Logo após o suicídio de Otto Weininger, August Strindberg escreveu a um amigo deste louvando a genialidade do autor de Sexo e Caráter, uma vez que ele havia conseguido resolver o maior dos problemas, ou seja, o problema da mulher (SMITH In HUEMER \& SCHUSTER 2003: 82).
} 


\section{Munk, L. - Micenas na Viena fin-de-siècle}

Em sua obra monumental, ele aponta que o modelo de sociedade patriarcal, cujos principais pilares seriam a propriedade individual e a divisão do trabalho, teria evoluído de uma comunidade matriarcal de fundamento agrário com fortes tendências igualitárias. Para um autor como Otto Weininger, por exemplo, tal revelação implicou não apenas o questionamento da vigência do direito patriarcal, como, sobretudo, o inevitável enfraquecimento da própria figura masculina, o que terminaria, segundo ele, por ocasionar o declínio da civilização europeia uma vez que a permanência do homem racional havia sido posta em questão. Esse pensamento algo apocalíptico, e inegavelmente mítico, encontrou grande ressonância entre os leitores de Sexo e caráter.

E embora tenha recorrido a alguns inquestionáveis documentos históricos, como a Biblioteca, do Pseudo-Apolodoro, e as Histórias, de Plutarco, onde se encontram afirmações de que o povo lício fora governado desde a Antiguidade pelas mulheres em uma comunidade que prescindia de leis escritas, Bachofen se serviu igualmente de símbolos e mitos que utilizava de modo indistinto como fontes históricas, o que resultou em sérias críticas por parte do mundo científico da época. Em suas notas para seu ensaio sobre o autor suíço, Walter BENJAMIN (1991: 967-8) observa que: “[...] Rarement il ne tient compte de la différence du mythe et de l'histoire / C'est le mythe qui l'intéresse avant tout // Il le cherche dans sa forme primitive, c'est à dire préhomérique [...]". ${ }^{3}$ Para Bachofen, o valor do mito residia em sua capacidade de representar todos os períodos da história dos povos primitivos. E foi precisamente esse interesse incondicional pelo mito e por seu resgate como instrumento de apreensão do humano que possibilitou o diálogo da obra com alguns de seus mais notáveis "continuadores", entre os quais se destacariam Karl Marx e Friedrich Engels, bem como Sigmund Freud, o já citado Nietzsche e Hugo von Hoffmannsthal.

É certo que, como observei em outra ocasião (MUNK 2011: 3), conquanto tenha contribuído imensamente para uma teoria do feminino, a obra de Bachofen não escapou às ambiguidades inerentes à época, haja vista sua constatação de que a passagem do matriarcado para o patriarcado se deu como uma necessária evolução da espécie humana rumo à civilização. Trata-se do mesmo antagonismo que seria posteriormente estudado de modo exemplar por Freud em seu O Mal-Estar na Civilização, a saber, que

\footnotetext{
3 "Raramente ele se dá conta da diferença do mito e da história / É o mito o que o interessa antes de tudo // Ele o procura em sua forma primitiva, isto é, pré-homérica”. [Tradução de Leonardo Munk, L. M.]
} 


\title{
Munk, L. - Micenas na Viena fin-de-siècle
}

as restrições do processo civilizacional e as exigências do instinto eram forças inevitavelmente opostas. A emancipação do homem, desse modo, passaria pela subtração dos desejos primitivos e arcaicos em nome de valores culturais. Esse é o resultado da transição da natureza para a cultura, comprovando que, para Freud, o processo de autodeterminação masculino se construiria em oposição à dispersão do feminino. E mesmo o deslocamento do patriarcado de sua posição centralizadora efetuado pela revolução copernicana instaurada pela Interpretação dos sonhos implicou em última análise a valorização do masculino em detrimento do feminino.

E mesmo atribuindo à mulher, pelo menos em uma etapa inicial do desenvolvimento humano, uma função educadora, a referência feita por Bachofen à adoração das mulheres a Dioniso ${ }^{4}$ termina por associar invariavelmente $\mathrm{o}$ comportamento feminino às características inerentes ao deus, tais como o afrouxamento de todos os sentidos e a liberação de toda inibição e repressão. Na mesma passagem, presente no capítulo referente aos orcômenos e aos mínios, Bachofen compara Dioniso, deus da metamorfose e da embriaguez, a Apolo, deus da serenidade e da estabilidade (Rossi 2009: 283). Essa comparação nos remete de pronto à dualidade dionisíacoapolínea apresentada por Nietzsche em sua primeira publicação, $O$ nascimento $d a$ tragédia ou helenismo e pessimismo. Ultrapassando Bachofen, porém, Nietzsche vislumbrava o dionisíaco como um complemento do apolínio e vice-versa.

\begin{abstract}
O encantamento é o pressuposto de toda a arte dramática. Nesse encantamento o entusiasta dionisíaco se vê a si mesmo como sátiro e como sátiro por sua vez contempla o deus, isto é, em sua metamorfose ele vê fora de si uma nova visão, que é a ultimação apolínea de sua condição. Com essa nova visão o drama está completo.
\end{abstract}

Nos termos desse entendimento devemos compreender a tragédia grega como sendo o coro dionisíaco a descarregar-se sempre de novo em um mundo de imagens apolíneo (NIETZSCHE 1999: 60).

A aceitação desse fato - ou seja, da constituição do caráter trágico da existência, representaria uma saída positiva para o niilismo que contaminava a Europa da segunda metade do século XIX. Estudando Nietzsche como pensador político, Keith Ansell-

\footnotetext{
${ }^{4}$ Embora a grafia Dionísio possa ser encontrada em alguns textos em português, sirvo-me da forma adotada pelas tradutoras Maria Helena Ribeiro da Cunha e Maria Cecília Queirós de Morais Pinto para o volume Dioniso: apologia do teatro, de autoria de Pierre-Aimé TOUCHARD (1978: 14).
} 


\section{Munk, L. - Micenas na Viena fin-de-siècle}

Pearson, professor de Filosofia na Universidade de Warwick, Inglaterra, faz uma pertinente leitura dessa dialética.

As duas divindades, Apolo e Dioniso, revelam a Nietzsche a profunda tensão em que os gregos viviam, como criaturas que só podiam superar o niilismo cultivando uma apreciação estética do espetáculo da vida - da vida como dor, sofrimento e autocontradição primordiais. Por intermédio da arte, os gregos adquiriram um sentido dionisíaco da unidade primordial da natureza e do homem e, ao mesmo tempo, foram resgatados de seus efeitos inebriantes por meio da agradável ilusão propiciada pelo apolíneo (ANSELL-PEARSON 1997: $80)$.

Relevante para Nietzsche era a ideia de que a emancipação de todo e qualquer tipo de opressão só poderia ser obtida por intermédio da arte. Essa premissa fundamental do pensamento nietzschiano poderia ser estendia a grande parte da produção intelectual e artística da Viena fin-de-siècle, incluindo até mesmo a produção científica de Freud, caso seja considerado o inegável valor poético de sua obra. Afinal, o mergulho nas profundezas da tragédia grega foi exatamente o que possibilitou a Freud esquadrinhar a psique do homem moderno.

Ao discorrer sobre a ambivalência de Freud acerca de suas investigações científicas, a saber, sua ora maior ora menor fidelidade à herança iluminista, Laurence COUPE (1997: 127), crítico literário e professor na Universidade Metropolitana de Manchester, Inglaterra, destaca o pesquisador que assume riscos de interpretação e que constantemente reescreve de modo radical o material que estuda, não ignorando os elementos míticos inerentes ao seu trabalho científico. Aquele mesmo fazedor de mitos que resgatou as mitologias da obscuridade, içando-as à condição de chave para penetrar nos mistérios do inconsciente. Por intermédio de A interpretação dos sonhos, Freud afirmou que o estudo dos mitos podia ser de grande auxílio na apreensão dos processos do inconsciente uma vez que aqueles, símiles dos sonhos, incorporariam elementos inconscientes que poderiam aludir a inúmeros significados dependendo do sujeito e de sua história.

Desse modo, ao situar o trauma em um tempo transcorrido, negando consequentemente a autoridade do passado ao modo de Nietzsche, Freud desestabilizou o presente introduzindo sexo, violência, repressão e culpa como elementos formadores da civilização humana. Tal desenterramento do passado pôs em xeque a noção da história enquanto um desenvolvimento linear, visto que os traumas sofridos em tempo pretérito teimariam sempre em retornar e assombrar o presente. Nessa perspectiva, a 


\title{
Munk, L. - Micenas na Viena fin-de-siècle
}

tranquilidade do presente seria uma ilusão, e somente seu confronto com as perturbadoras forças do passado possibilitaria a superação dos traumas. Mais uma curiosa aproximação do Nietzsche do eterno retorno.

Thus Freud looks backwards from the neuroses of the modern individual to the Oedipus myth; and then he looks further back, to the 'primal crime'. In order to understand the urge to remember, return and repeat, he does exactly what he sees his own patients doing. Thus his account of mythic thinking is itself mythic. Moreover, his myth is one that obliterates reassuring distinctions, most notably that between history and pre-history, and that between civilization and savagery, as he orients all his evidence back to a founding sexual trauma. This runs the risk of being reductive, but the effect is more likely to be creatively disorienting. Sacred memory and sexual drive are played off against each other dialectically (COUPE 1997: 130). ${ }^{5}$

É importante observar, no entanto, como para Freud essa contínua repetição psicológica do crime primordial - ou antropológica uma vez que no dizer de SCHORSKE (1990: 195): “[...] a história pessoal se une ao coletivo a-histórico" - estava imbuída de uma função necessariamente terapêutica. Acerca disso, John E. Toews, diretor do Programa de História Comparada das Ideias na Universidade de Washington, faz a seguinte observação:

\begin{abstract}
A força da história de Édipo está em ela nos obrigar a reconhecer em toda a sua extensão o nosso dilema ético e, por conseguinte, as únicas vias autênticas ou viáveis para sua possível "resolução". [...] Uma vez reconstruída essa lembrança, a história da formação dos sintomas patológicos tornava-se "evidente" e sua "lógica" interna, coerente. A lembrança recalcada do trauma podia então ser conscientemente integrada na história de vida do paciente, desfazendo-se sua carga afetiva patológica. Depois que o evento traumático - e o culpado - eram recordados e nomeados, o paciente podia recuperar a coerência narrativa e o autodomínio de que fora privado (TOEWS in ROTH 2000: 65-66).
\end{abstract}

Seja em termos psicanalíticos, seja em termos antropológicos, o fato é que o recurso ao mito por parte de Freud se revestiu desde o primeiro momento de uma tendência inegavelmente afirmativa. E é sob esse aspecto que se pode atribuir a Freud a alcunha de pensador iluminista. Nesse sentido, a clara preferência de Freud pela figura da deusa

\footnotetext{
5 "Destarte Freud olha para trás, da neurose do indivíduo moderno ao mito de Édipo, e então ele olha ainda mais para trás, para o "crime primordial". A fim de compreender o desejo de lembrar, voltar e repetir, ele faz exatamente o que ele vê seus próprios pacientes fazendo. Assim sua interpretação do pensamento mítico é ele próprio mítico. Além disso, seu mito é aquele que elimina distinções reconfortantes, sobretudo, aquelas entre história e pré-história, e aquelas entre civilização e selvageria, enquanto ele orienta todas as suas evidências de volta para um trauma sexual fundador. Corre o risco de ser reducionista, mas o efeito é mais provável que seja criativamente desorientador. Memória sagrada e desejo sexual são jogados uns contra os outros dialeticamente". [Tradução de L. M.]
} 


\section{Munk, L. - Micenas na Viena fin-de-siècle}

Atena é um evidente demonstrativo de seu desejo de controlar as forças irracionais que ironicamente ele próprio se encarregara de invocar. A esse respeito, SCHORSKE (2000: 226) chega a adicionar o adjetivo "romano" a Atena de Freud - salientando, propositalmente, as clássicas distinções entre as culturas grega e romana - ao se questionar se esta seria a mesma escolhida pelos liberais de Viena como símbolo da justiça e da razão.

A resposta para tal questão não poderia, no entanto, ser respondida com simplicidade uma vez que as próprias certezas de Freud acerca da validade do Complexo de Édipo como a base de toda civilização humana seriam posteriormente postas em dúvida. Em um texto de 1931, ele diz o seguinte:

Há muito tempo renunciamos à expectativa de um perfeito paralelismo entre o desenvolvimento sexual masculino e o feminino.

A percepção da anterior fase pré-edípica da garota é para nós uma surpresa, semelhante à descoberta, em outro campo, da civilização minoico-micênica por trás da grega.

Tudo, no âmbito dessa primeira ligação com a mãe, pareceu-me bastante difícil de apreender analiticamente, bastante remoto, penumbroso, quase impossível de ser vivificado, como se tivesse sucumbido a uma repressão particularmente implacável. Mas talvez esta impressão me viesse do fato de que as mulheres podiam se apegar, na análise comigo, à mesma ligação ao pai em que se haviam refugiado após a fase anterior em questão [...] Não consegui penetrar inteiramente nenhum caso, por isso me limitarei a expor os resultados mais gerais e a oferecer alguns exemplos de minhas novas percepções. (FREUD 2010: 285-6).

E é a esse universo arcaico - ou pré-edípico, caso se prefira -, e consequentemente “irracional”, que os modernos de Viena irão recorrer a fim de escaparem da opressão da razão burguesa. Como contraponto a esta, ter-se-ia o desejo de um mundo feminino conduzido por heroínas míticas como Antígona, Ariadne e Electra. Invariavelmente oprimidas por uma ordem masculina - ou que pelo menos a esta se igualam -, essas alegorias distantes do classicismo humanizado de um Johann Joachim Winckelmann, o historiador da arte responsável pela ascensão do neoclassicismo alemão, propunham um caminho inverso à lei do Pai.

No caso do poeta e dramaturgo Hugo von Hofmannsthal, que nutria um real interesse pela psicanálise, a intenção de escrever um drama sobre Electra se originou do desejo de se contrapor a uma visão da Grécia como a elaborada por Johann Wolfgang von Goethe em sua Ifigênia em Táuride, cuja versão definitiva data de 1786. Nesta, 


\section{Munk, L. - Micenas na Viena fin-de-siècle}

todos os traços arcaicos inerentes ao mito haviam sido substituídos por elementos classicizantes. A esse respeito, Anatol Rosenfeld diz que:

Goethe decantou a sua protagonista em ampla medida do fundo telúricodemoníaco. Ela vive em Táuride, banhada em luz apolínea, "com a alma a terra dos gregos procurando". O exílio, longe do céu olímpico, significa-lhe outra morte, a segunda após o sacrifício desfeito. A sua personagem parece uma encarnação (não muito carnal) do sonho clássico de Winckelmann que via os gregos através de uma aura de "nobre simplicidade e serena grandeza". (ROSENFELD 1997: 15).

Ao invés de Goethe e Winckelmann, Hofmannsthal dialoga com Nietzsche e Freud. No lugar das tradicionais colunas gregas, ele propõe (HoFMANNSTHAL 1979: 240), em suas indicações cênicas, uma arquitetura de estilo oriental que se mostre misteriosa e estranha aos olhos do público europeu. Essa concepção orientalizante, herdada da Escola da Basiléia de Burckhardt e Bachofen, defendia que o helenismo clássico havia se constituído a partir de uma organização de ideias e deuses vindos do oriente (LE RIDER 1993: 259). Nessa opção pelo orientalismo, Hofmannsthal revela seu fascínio por uma Grécia "original” que teria o deus Dioniso como sua representação mais autêntica. Em um ensaio de 1892, ele demonstrava sua paixão ao divagar sobre uma Grécia órfica obscurecida pelas paixões.

[...] a vida se mostrava sob uma máscara de Medusa, com olhos enigmáticos e angustiantes; como no luto de Adônis, no culto de Cibele, os calafrios da vida mais desenvolvida e os da morte se confundiam; e Dionísio caminhava, deus risonho e mortal, através de um mundo inquietante e repleto de vida. (HOFMANNSTHAL apud LE RIDER 1993: 259).

Esse mundo regido pelo matriarcado, cujo ocaso segundo Bachofen já se delineava nas obras de Ésquilo, Oréstia, e Eurípides, Medéia (Rossi, 2009: 280), era, portanto, aquele que interessava a Hofmannsthal. Sua Electra, de 1903, também é uma releitura de uma heroína trágica, e nesse sentido não se afasta, por exemplo, da Ifigênia de Goethe. No mais, são em tudo distintas, pois ao se servir desse célebre mito antigo - o assassínio de Clitemnestra e seu amante Egisto pelas mãos de seus filhos Orestes e Electra, Hofmmansthal ambicionava, à maneira de Freud em seus estudos teóricos, investigar a alma desses personagens, tornando-os vivos para uma audiência do século XX. Sob esse aspecto, a pesquisadora Anastasia Bakogianni, do departamento de Grego e Latim da University College de Londres, em um interessante texto no qual disserta acerca das 


\section{Munk, L. - Micenas na Viena fin-de-siècle}

diferenças das versões operísticas de W. A. Mozart e Richard Strauss (com o texto dramático de Hoffmannsthal como libreto) para a história de Electra, diz o seguinte:

It is in the twentieth century that Electra became a protagonist again rather than a minor character. The changes brought about by the Industrial Revolution in the nineteenth century and women's campaign for the vote transformed the face of society. Freud's theories of hysteria (Freud and Breuer 1991) renewed interest in women ruled by extreme emotion, thus making Electra popular again for the very reason that had caused her loss of prominence before (BAKOGIANNI 2007: 02). ${ }^{6}$

Ao contrário da versão de Mozart (e do libretista italiano Giambattista Varesco), de 1781, a Electra de Strauss (e Hofmannsthal), de 1909, ocupa o centro do palco, assumindo uma importância que não possuía nem mesmo nas obras dos tragediógrafos gregos. LE RIDER (1993: 261) informa-nos, inclusive, que para Hofmannsthal seu texto seria uma obra mais bela e perfeita caso a personagem de Orestes estivesse simplesmente ausente dela. Tal opinião apenas confirma a radical mudança de foco das Electras clássicas para a vienense, pois o jogo cênico, no caso do texto de Hoffmannsthal, diz respeito quase que exclusivamente ao confronto entre mãe e filha, ou seja, Clitemnestra e Electra. Mesmo as referências às questões de estado e religião tão vigorosas e essenciais às versões gregas - são minimizadas em nome de problemas privados, quase estudos de caso - a exemplo dos célebres tratamentos de Anna O. e Dora -, como o obsessivo desejo de vingança de Electra, por um lado, e a memória reprimida de Clitemnestra em outro. Tem-se aqui uma clara adesão tanto às teorias esboçadas por Freud e Josef Breuer em Estudos sobre a histeria, publicado pela primeira vez em 1893, quanto às análises propostas em A interpretação dos sonhos. Da leitura dessas obras uma descoberta que produziu profundos abalos: o inconsciente é regido por desejos primitivos e irracionais de natureza sexual e/ou destrutiva.

A pulsão sexual é sem dúvida a fonte mais poderosa de acúmulos sistemáticos de excitação (e, por conseguinte, de neuroses). Esses aumentos distribuem-se de maneira muito desigual pelo sistema nervoso. Quando alcançam um grau considerável de intensidade, o encadeamento de ideias fica perturbado e o valor

\footnotetext{
6 “É no século XX que Electra se tornou protagonista de novo, ao invés de um personagem menor. As mudanças trazidas pela Revolução Industrial no século XIX e da campanha das mulheres pelo voto transformaram a face da sociedade. As teorias de Freud sobre a histeria (Freud e Breuer 1991) renovaram o interesse em mulheres governadas pela emoção extrema, tornando Electra popular novamente pela mesma razão que havia causado sua anterior perda de destaque". [Tradução de L. M.]
} 


\section{Munk, L. - Micenas na Viena fin-de-siècle}

relativo das ideias se altera; e no orgasmo o pensamento é quase inteiramente extinto.

Também a percepção - a interpretação psíquica das impressões sensoriais - é prejudicada. Um animal normalmente tímido e cauteloso torna-se cego e surdo ao perigo. Por outro lado, pelo menos nos machos, há uma intensificação do instinto agressivo. Os animais pacíficos ficam perigosos, até a sua excitação ser descarregada nas atividades motoras do ato sexual (FREUD \& BREUER 1980: 151).

Ao contrário das versões clássicas de Electra, onde esta, apesar de relegada a condição de escrava, jamais perde a dignidade que convinha às grandes heroínas, a de Hoffmannsthal atinge um estágio de condição quase animal. E é como um animal feroz em busca de vingança pela morte do pai - e do consequente exílio do irmão -, que ela é descrita pelas servas que a temem.

\section{Magd ihr Wassergefäss aufhebend:}

\section{Magd}

Wo bleibt Elektra?

Ist doch ihre Stunde, die Stunde, wo sie um den Vater heult, dass alle Wände schallen.

Elektra kommt aus der schon dunkelnden Hausflur gelaufen. Alle drehen sich nach ihr um. Elektra springt zurück wie ein Tier in seinen

Schlupfwinkel, den einen Arm vor dem Gesicht.

I. Magd

Habt ihr gesehn, wie sie uns ansah?

\section{Magd}

Giftig

wie eine wilde Katze.

\section{Magd}

Neulich lag sie

da und stöhnte - (HOFMANNSTHAL 1979: 187) ${ }^{7}$

A vingança é o sentimento que a move, algo distante, portanto, dos nobres sentimentos que conduziam as heroínas de Ésquilo e Sófocles. Seu comportamento, que beira a bestialidade, é um ingrediente altamente subversivo em qualquer sociedade ordenada. É curioso que apesar de sua feminilidade, a Electra tradicional exerça o papel de agente

\footnotetext{
7 " 1 a Serva (levantando seu vaso): Onde está Electra?

$2^{a}$ Serva: Não é a hora, a hora em que ela lamenta por seu pai, e que todas as paredes ecoam?

(Electra sai do corredor escuro. Todas se voltam para ela. Electra pula de volta como um animal em seu covil, o braço diante do rosto)

$1^{\text {a }}$ Serva: Vocês viram como ela nos olhou?

$2^{a}$ Serva: Venenosa como uma gata selvagem.

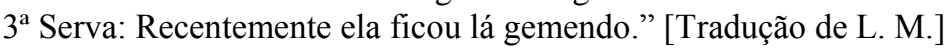




\title{
Munk, L. - Micenas na Viena fin-de-siècle
}

restaurador da antiga ordem, ou seja, da autoridade patriarcal perdida após o brutal assassinato de Agamemnon pelas mãos de Clitemnestra e de seu amante. A ordem patriarcal será restabelecida ao preço de um matricídio. Sobre essa questão, Annunziata Rossi, professora da Universidade Nacional Autônoma do México, comentando a parte final da trilogia de Ésquilo, a Oréstia, faz um interessante comentário:

Orestes, el hijo de ambos, para vengar al padre mata a la madre. Por ello, las Euménides, guardianas del orden materno todavía vigente, intervienen para enjuiciarlo, y cuando él les pregunta por qué no habían castigado a la asesina, ellas contestan: "No era consanguínea del hombre al que mató". Matar a la madre, con la que se tienen vínculos de consanguinidad, era la peor trasgresión de las normas inviolables del derecho materno, cualquiera que hubiese sido su motivación. Sin embargo, las Euménides terminan doblegándose a Atenea y Apolo, es decir, a los dioses del principio paterno (Rossi 2009: 286-7). ${ }^{8}$

Também na obra de Hofmannsthal (e Strauss) é perceptível o modo como a anarquia e a barbárie patrocinadas pelo casal assassino são substituídas pela ordem de Orestes. Aparentemente corporificando a lei do Pai, - a lei de Agamemnon, aquele que passa de protetor a opressor -, a Electra de Hofmannsthal se volta contra a lei da Mãe representada pela dupla Clitemnestra/Egisto. Quanto a isso, há de se atentar para a feminilização do personagem Egisto, presente já na Oréstia de Ésquilo. Nas Coéforas, primeira parte da trilogia, Orestes afirma que o coração de Egisto é de mulher, ou seja, o governo de Micenas estaria sob o controle de duas mulheres.

\begin{abstract}
ORESTES
[...] Inda que não lhe desse crédito o feito se consumaria, pois impulsos me impelem sempre para uma conclusão: além do mandamento nítido de Apolo, a dor profunda pela morte de meu pai, as ameaças da pobreza detestável e sobretudo o desejo de não deixar nossos concidadãos, vencedores em Tróia graças à sua resoluta valentia, serem escravizados por duas mulheres (de fato, o coração de Egisto é de mulher; se ele não sabe, logo ficará sabendo!) (ÉSQUILO 1991: 103).
\end{abstract}

Nesse contexto, LE RIDER (1993: 263) observa que o próprio Hofmannsthal teria afirmado alguns anos depois que Electra trabalharia para o retorno da harmonia no mundo. Contudo, embora esteja destinada a reencontrar Orestes e a restaurar a ordem da casa paterna, a fúria excessiva de Electra, e também nesse aspecto a anti-heroína de

\footnotetext{
8 “Orestes, o filho de ambos, para vingar o pai mata a mãe. Por conseguinte, as Eumênides, guardiãs da ordem materna vigente, intervêm para julgá-lo e quando ele as questiona porque não haviam castigado a assassina, elas respondem: "Não era consanguínea do homem que matou". Matar a mãe, com quem se tem vínculos de consanguinidade era a pior transgressão das normas invioláveis do direito materno, qualquer que houvesse sido a motivação. Contudo, as Eumênides terminam dobrando-se perante Atena e Apolo, quer dizer, aos deuses do princípio paterno. [Tradução de L. M.]
} 


\section{Munk, L. - Micenas na Viena fin-de-siècle}

Hofmannsthal é única, poderá conduzi-la à destruição. Em outra cena fundamental, quando mãe e filha conversam após longos anos de afastamento, a fala de Clitemnestra causa surpresa ao mostrar ignorância de dois fatos fundamentais no desenrolar da maldição da casa de Agamemnon: o assassinato sacrificial de Ifigênia pelo pai e a posterior morte deste quando de seu retorno de Tróia.

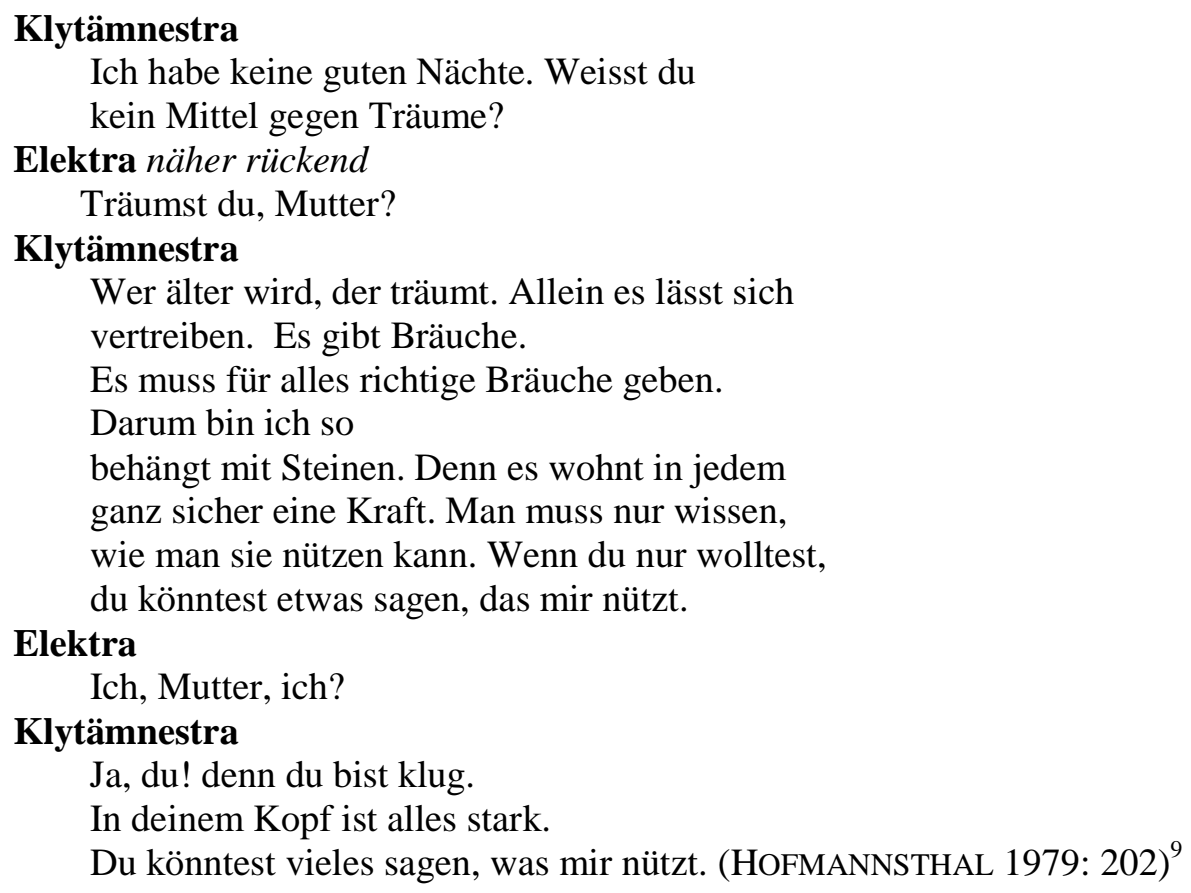

Traumatizada pelas experiências passadas, a Clitemnestra de Hofmannsthal vaga como uma sonâmbula, guardando, por conseguinte, espantosa semelhança com as pacientes examinadas por Freud e Breuer no já citado Estudos sobre a histeria. "Posso afirmar que esse esquecimento é muitas vezes intencional e desejado, e seu êxito nunca é mais do que aparente" (FREUD \& BREUER 1980: 90). Como é sabido, Breuer e Freud perceberam que poderiam decodificar o sentido dos sintomas por intermédio da fala, abolindo desta feita o tratamento da hipnose. Ao que parece, no entanto, Electra, ao trocar o papel de histérica pelo de analista, é incapaz de oferecer qualquer redenção a

\footnotetext{
${ }^{9}$ Clitemnestra: Eu não tenho tido boas noites de sono. Você conhece algum recurso contra sonhos? Electra (aproximando-se): Sonhas, mãe?

Clitemnestra: Aquele que envelhece sonha. Há maneiras de evitá-los. Há ritos. Para tudo deve haver os meios certos. Por isso eu ando sempre adornada com pedras. Em cada uma delas reside uma força. É preciso apenas saber como usá-las da melhor maneira. Se você quisesse você poderia me dizer algo.

Electra: Eu, mãe, eu?

Clitemnestra: Sim, tu! Tu és sábia. A tua cabeça é forte. Você poderia dizer muitas coisas úteis para mim. [Tradução de L. M.]
} 
Munk, L. - Micenas na Viena fin-de-siècle

Clitemnestra, da mesma forma que a própria visão de Hofmannsthal prescinde de qualquer tipo de consolo. Mesmo o amor pode destruir, e isso apesar da internalização de regras defendida por Freud como elemento imprescindível para a manutenção do processo civilizacional (BRUNNER in ROTH 2000: 77).

Reconduzido ao seu lugar de direito no final do drama, Orestes restaura a ordem patriarcal, afinal, como o próprio Freud já afirmara, “O pai é a primeira, a mais antiga e, para os filhos, a única autoridade e de seu poder autocrático emergiram as outras autoridades sociais no decorrer da civilização humana" (apud TOEWS in ROTH 2000: 70). Seguindo essa advertência, poder-se-ia perguntar se há verdadeiramente um lugar para Electra nesse cenário. Sua morte ao final da obra, exclusividade de Hofmannsthal, parece comprovar esse não-lugar, uma vez que a restauração da ordem vigente só se torna possível mediante a própria dissolução da protagonista. Negando a emulação da lei do Pai, a morte de Electra - corporificada em uma dança dionisíaca -, poderia nessa perspectiva apontar para outra possibilidade, uma terceira via em meio aos destroçados valores masculinos de Agamemnon e o fracasso da utopia do matriarcado representado por Clitemnestra e Egisto.

\section{Referências bibliográficas}

AnSELl-PeARSON, Keith. Nietzsche como pensador político - uma introdução. Tradução de Mauro Gama e Claudia Martinelli Gama. Rio de Janeiro: Jorge Zahar Ed., 1997.

BAKOGIANNI, Anastasia. An eighteenth-century jealous woman and a twentieth-century hysterical diva: the case of Mozart's Idomeneo (1781) and Strauss' Elektra (1909). New Voices in Classical Reception Studies, 2 pp. 1-32. 2007. Disponível em: http://oro.open.ac.uk/21306/1/bakogianni2007.pdf, acesso em 20 de julho de 2012.

BAuman, Zygmunt. O mal-estar da pós-modernidade. Tradução de Mauro Gama e Cláudia Martinelli Gama. Rio de Janeiro: Jorge Zahar Ed., 1998.

BENJAMIN, Walter. Gesammelte Schriften II. Frankfurt am Main: Suhrkamp, 1991.

BREUER, Josef; Freud, Sigmund. Estudos sobre a histeria. Volume II (1893-1895). Rio de Janeiro: Imago, 1980.

BRUNNER, José. Oedipus politicus: O paradigma freudiano das relações sociais. In: RoTH, Michael S. (org.) Freud, conflito e cultura: ensaios sobre sua vida, obra e legado. Tradução de Vera Ribeiro. Rio de Janeiro: Jorge Zahar Ed., 2000.

ChAves, Ernani. Kátharsis versus Ouvinte Estético: sobre a tragédia em Nietzsche e Walter Benjamin. In: DUARTE, Rodrigo; FIGUEIREDO, Virginia; FREITAS, Verlaine; KANGUSSU, Imaculada (orgs.). Katharsis: reflexos de um conceito estético. Belo Horizonte: C/Arte, 2002.

Coupe, Laurence. Myth. The New Critical Idiom. London and New York: Routledge, 1997.

DIMEN, Muriel. Corações estranhos: Da relação paradoxal entre a psicanálise e o feminismo. In: ROTH, Michael S. (org.) Freud, conflito e cultura: ensaios sobre sua vida, obra e legado. Tradução de Vera Ribeiro. Rio de Janeiro: Jorge Zahar Ed., 2000. 
Munk, L. - Micenas na Viena fin-de-siècle

ÉSQUILO. Oréstia. Tradução de Mário da Gama Kury. RJ: Jorge Zahar Editor, 1991.

FREUD, Sigmund. O mal-estar na civilização, novas conferências introdutórias e outros textos (1930-1936). Obras completas volume 18. Tradução de Paulo César de Souza. São Paulo: Companhia das Letras, 2010.

Hofmannsthal, Hugo von. Gesammelte Werke. Dramen II 1892-1905. Frankfurt am Main: Fischer Taschenbuch Verlag, 1979.

LE RIDER, Jacques. A Modernidade Vienense e as crises de identidade. Tradução de Elena Gaidano. Rio de Janeiro: Civilização Brasileira, 1993.

MAHONY, Patrick J. O mundo freudiano do trabalho. In: RoTH, Michael S. (org.) Freud, conflito e cultura: ensaios sobre sua vida, obra e legado. Tradução de Vera Ribeiro. Rio de Janeiro: Jorge Zahar Ed., 2000.

MunK, Leonardo. De Oskar Kokoschka a Heiner Müller: de um expressionismo a outro. In: Anais do XII Congresso Internacional da Associação Brasileira de Literatura Comparada. Curitiba: ABRALIC, 2011, e-book. Disponível em: http://www.abralic.org.br/anais/cong2011/AnaisOnline/resumos/TC0732-1.pdf, acesso em 20 de julho de 2012.

NiETZSCHE, Friedrich. O Nascimento da Tragédia ou Helenismo e Pessimismo. Tradução de Jacó Guinsburg. SP: Companhia das Letras, 1999.

Rosenfeld, Anatol. Teatro Moderno. Coleção Debates. 2a ed. São Paulo: Perspectiva, 1997.

RossI, Annunziata. J.J. Bachofen y el retorno de las madres. Acta Poetica 30(1), 2009, $275-$ 293. Disponível em: http://www.revistas.unam.mx/index.php/rap/article/ view/23140, acesso em 22 de julho de 2012.

RoudinesCO, Elisabeth. Genealogias. Tradução de Nelly Ladvocat Cintra. Rio de Janeiro: Relume-Dumará, 1995.

SCHORSKE, Carl E. Viena fin-de-siècle: política e cultura. Tradução de Denise Bottmann. São Paulo: Companhia das Letras, 1990.

SCHORSKE, Carl E. Pensando com a história: indagações na passagem para o modernismo. Tradução de Pedro Maia Soares. São Paulo: Companhia das Letras, 2000.

SMITH, Barry. Kraus on Weininger, Kraus on women, Kraus on Serbia. In: HuERMER, Wolfgang; SCHUSTER, Marc-Oliver. Writing the Austrian traditions: relations between philosophy and literature. Alberta: University of Alberta, 2003.

ToEws, John E. Ter e ser: A evolução da teoria freudiana do Édipo como fábula moral. In: RoTH, Michael S. (org.) Freud, conflito e cultura: ensaios sobre sua vida, obra e legado. Tradução de Vera Ribeiro. Rio de Janeiro: Jorge Zahar Ed., 2000.

TOUCHARD, Pierre-Aimé. Dioniso: apologia do teatro/O amador de teatro ou A regra do jogo. Tradução de Maria Helena Ribeiro da Cunha e Maria Cecília Queirós de Morais Pinto. SP: Cultrix, 1978.

Recebido em 01 de agosto de 2012

Aprovado em 17 de setembro de 2012 